\title{
Depressor Anguli Oris in IVF Twins
}

\author{
Abdullah Baris Akcan, ${ }^{1,}$ Mediha Akcan, ${ }^{2}$ and Servet Ozkiraz ${ }^{3}$ \\ ${ }^{1}$ Adnan Menderes University School of Medicine, Department of Pediatrics, Division of Neonatology, Aydin, Turkey \\ ${ }^{2}$ Adnan Menderes University School of Medicine, Department of Pediatrics, Aydin, Turkey \\ ${ }^{3}$ Baskent University School of Medicine, Department of Pediatrics, Division of Neonatology, Ankara, Turkey \\ "Corresponding author: Abdullah Baris Akcan, Adnan Menderes University School of Medicine, Department of Pediatrics, Division of Neonatology, Aydin, Turkey. Tel: \\ +90-2562142040, Fax: +90-2562136064, E-mail: barisakc@hotmail.com
}

Received 2015 August 09; Accepted 2016 January 28.

Keywords: Depressor Anguli Oris, IVF, Congenital Anomlies

\section{Dear Editor,}

Delaying conception has increased the demand on assisted reproduction. Currently, more than $1 \%$ of children are conceived through assisted reproductive technologies (ART) worldwide and this number is likely to continue increasing (1). Like any other medical intervention ART is associated with both short-term and longterm complications. IVF pregnancies may be at increased risk for multiple pregnancies, preterm birth, low birth weight, congenital anomalies, and perinatal mortality. It has long been known that the rate of congenital malformations is somewhat increased among infants born after in vitro fertilization (IVF). Risks of neural tube defects, orofacial clefts, cardiac defects, alimentary tract atresia, and hypospadias were increased. Possible association between IVF and the occurrence of imprinting anomalies, which can cause rare conditions such as Angelman syndrome, Beckwith-Wiedemann syndrome, Prader-Willi syndrome, russell-silver syndrome, UPD 14 syndrome, pseudohypoparathyroidism $1 \mathrm{~b}$, transient neonatal diabetes mellitus, and maternal hypomethylation syndrome $(2,3)$.

In our cases, premature twins were born by ceserean section to a 38-year-old gravida 2, para 2 female. The mother had uncomplicated antenatal course. Infants were born after IVF (double embryo transfer). A prenatal ultrasound and NST were normal. At birth there were no problems. Apgar score was 9 at 1 and 5 minutes. During a routine physical examination, asymmetric cryıng face was noticed in both of twins; the right corner of the mouth drew right and downward, while the left corner did not move. Their extra-ocular movements were intact with perfect closure of the eyes. They were presumed to have asymmetric crying facies (ACF) secondary to hypoplasia of depressor anguli oris. Their echocardiogram and cranial MRI investigations was normal. Their chromosome and FISH analysis were normal.
ACF is a minor anomaly, which presents with drooping of the corner of the mouth on the unaffected side when cying or grimacing and seen in $0.5 \%-1 \%$ of newborns. It is caused by either agenesis or hypoplasia of the depressor anguli oris muscle. ACF has been associated with other congenital anomalies in $20 \%$ to $70 \%$ of cases. Most anomalies are found in the head/neck and cardiovascular systems but they can also involve the skeletal, genitourinary, and gastrointestinal systems. In particular, ACF has been associated with the 22q11 deletion syndrome $(4,5)$.

In summary, we report IVF twins with ACF. They were first IVF cases with ACF in the literature. We conclude that the general risk for a congenital malformation after IVF and some rare malformation syndromes are over represented among infants born after IVF and a multidisciplinary team should follow these patients, with screening for complications and appropriate management.

\section{References}

1. Patchava S, Gelbaya TA, Nardo LG. Managing the complications associated with assisted reproductive technologies. Minerva Ginecol. 2009;61(4):347-55. [PubMed: 19745799].

2. Hansen M, Bower C, Milne E, de Klerk N, Kurinczuk JJ. Assisted reproductive technologies and the risk of birth defects-a systematic review. Hum Reprod. 2005;20(2):328-38. doi: 10.1093/humrep/deh593. [PubMed: 15567881].

3. Hansen M, Kurinczuk JJ, Milne E, de Klerk N, Bower C. Assisted reproductive technology and birth defects: a systematic review and meta-analysis. Hum Reprod Update. 2013;19(4):330-53. doi: 10.1093/humupd/dmt006. [PubMed: 23449641].

4. Lahat E, Heyman E, Barkay A, Goldberg M. Asymmetric crying facies and associated congenital anomalies: prospective study and review of the literature. J Child Neurol. 2000;15(12):808-10. [PubMed: 11198496].

5. Jones KL, Adam MP. Evaluation and diagnosis of the dysmorphic infant. Clin Perinatol. 2015;42(2):243-61. doi: 10.1016/j.clp.2015.02.002. [PubMed: 26042903]. 